\title{
Stage IIIB Uterine Corpus Adenosarcoma AJCC v8
}

National Cancer Institute

\section{Source}

National Cancer Institute. Stage IIIB Uterine Corpus Adenosarcoma A/CC v8. NCI

Thesaurus. Code C139902.

Stage IIIB includes: T3b, N0, M0. T3b: Uterine corpus adenosarcoma with tumor infiltrating abdominal tissues at more than one site. NO: No regional lymph node metastasis. M0: No distant metastasis. (AJCC 8th Ed.) 